\title{
The effectiveness of dear healthcare professional letters as a risk minimization tool in Ghana
}

\author{
George Tsey Sabblah*, Delese Mimi Darko, Abena Asamoa-Amoakohene and Adela Ashie \\ Safety Monitoring and Clinical Trials Division, Food and Drugs Authority, Ghana.
}

Received 22 June, 2016; Accepted 29 August, 2016

\begin{abstract}
Dear Healthcare Professional (DHP) letter is a risk minimization tool used to inform health workers about new and emerging safety information during the marketing period of medicinal products. DHP letters in some cases may not be effective because targeted audience may not be aware of these letters or even understand them. The objectives of this study were to assess the effectiveness and relevance of DHP letters as effective risk minimization tool and to seek opinion of health workers about the most effective way of communicating safety information. A descriptive correlational study of 913 health workers selected by convenient sampling through face-to-face interviews from Apr. to June, 2014 was conducted, with a response rate of $83.15 \%$. The data was analyzed using descriptive analysis and Pearson-chi square test $\left(x^{2}\right)$ with STATA version 13. A p-value of $<0.05$ was considered significant during the analysis. Of the 913 respondents only $350(38.34 \%)$ were aware of at least one of the letters distributed in 2013 and $314(89.71 \%)$ out of these admitted that these letters have influenced their way of prescribing, dispensing and administering the medicines involved. One hundred and ninety-two $(54.82 \%)$ of the respondents rated the level of understanding of the language used as good and there was no significant difference in the health workers rating of the language used in the letters $(p=0.40)$. Health workers suggested electronic methods such as short messaging service to their mobile phones $56.81 \%(438)$, e-mail $91(85.85 \%)$ and posting the letters on the Food and Drugs Authority's website $26.85 \%$ (207). The results suggest that DHP letters issued by the Food and Drugs Authority (FDA) are effective in changing behavior of those who receive them but they are received late or not at all. The FDA should therefore explore other means of communicating safety information such as electronic means as suggested by the health workers.
\end{abstract}

Key words: Ghana, dear healthcare professional letter, risk minimization, effectiveness.

\section{INTRODUCTION}

A Dear Healthcare Professional (DHP) letter is a correspondence usually in the form of a mass mailing from the marketing authorization holder of medicinal product or a regulatory authority addressed to doctors, pharmacists, nurses and other health workers regarding important new safety information (USFDA, 2010). DHP

*Corresponding author. Email: georgesabblah@gmail.com. Tel: +233 266171661.

Author(s) agree that this article remain permanently open access under the terms of the Creative Commons Attribution License 4.0 International License 
letters are intended to inform the recipients of the need to take certain action(s) or adopt certain practices to minimize particular risks and/or to reduce burden of adverse drug reactions with a medicinal product (EMA, 2014).

Throughout the life cycle of a marketed drug, new safety information emerges; some of which may lead to disability, hospitalization and even death of patients which must be communicated to health workers to ensure patient safety and to minimize the risk of adverse events. There are several risk minimization measures for communicating safety information to health workers, including press releases, black box warnings, changes in the summary of product characteristics and DHP letters. The most common and preferred method of communicating safety information is through the DHP letters (Piening et al., 2012; Théophile et al., 2011). Studies have revealed that about 10 to $14 \%$ of the registered medicinal products require DHP letters to inform health workers about newly identified risks within the first 3 years of their marketing authorization and also about $22 \%$ of drugs issued marketing authorization are withdrawn within the first 6 years for safety reasons which must be communicated to health workers to ensure patient safety (Arnardottir et al., 2011; Giezen et al. 2008; Qureshi et al., 2011).

The main goal of DHP letters as a risk minimization tool is to minimize the occurrence of safety issues. They are also used to communicate new or emerging safety information on medicines to health workers and the content and wording of these letters are extremely important in achieving the intended purpose. Review of the literature suggested that letters to health workers may or may not be effective in communicating safety information leading to change in behavior (Dusetzina et al., 2012; Piening et al., 2012).

The impact of four DHP letters was examined and label changes on the monitoring of serum enzymes for liver toxicity among patients on troglitazone and found that an early impact on increased monitoring behavior (from 15 to $45 \%$ ) was not sustained during the six-month study period (Graham et al., 2001). The Mazor study evaluated the quality of a group of DHP letters sent by pharmaceutical companies between 2000 and 2001 which were intended to communicate important new drug safety information. The study found a correlation between the quality or perceived quality of DHP letters and the extent to which physicians perceive the new information as important. Letters that were evaluated as clearer, more concise, better organized and formatted, and focused on the most important aspects of the new safety information were also considered to be more effective in communicating the new information (Mazor et al., 2005).

Reiber et al. (2012) examined the effect of DHP letters on the prescription of specialist and non-specialist drugs and found that DHP letters had less impact on use of specialist drugs than non-specialist drugs $(P<0.05)$. The study concluded that the risk communication can be effective, specifically in case of well-structured information, and very serious safety issues potentially causing death or disability (Reber et al., 2012). In 2013, the Ghana Food and Drugs Authority (FDA) issued 6 DHP letters to health workers through an approved mailing list and also via the FDA's website, www.fdaghana.gov.gh on varying safety issues (Food and Drugs Authority Ghana, 2013a, b, c, d, e, f). The letters address safety issues concerning azithromycin and cardiovascular risks; the risks involved with the use of codeine for analgesia in children and adolescents; diclofenac and the risk of cardiovascular events; paracetamol and the risk of severe skin reactions; reporting incidents of therapeutic ineffectiveness and restrictions on the use of ketoconazole due to severe liver injury, adrenal gland problems and drug interactions.

Implementation and evaluation of the effectiveness of risk minimization measures is evolving and the European Medicines Agency has made provisions which require marketing authorization holders and regulatory authorities to monitor the effectiveness of risk minimization measures. Similarly, the United States, Food and Drug Administration may also require risk evaluation and mitigation strategy (REMS) for registered medicinal products to minimize or reduce the impact of adverse events (USFDA, 2009). However, the provisions in good pharmacovigilance practices (GVP) module $\mathrm{XVI}$ is not clear on the exact methodology for evaluating the effectiveness of the risk minimization measures (EC, 2010; EMA, 2014; Raine et al., 2011). In addition to this shortcoming, to the best of our knowledge this is the first study to evaluate the effectiveness of risk minimization measure in a developing country setting. This research therefore provides important missing information regarding the effectiveness of DHP letters as an important risk minimization tool in communicating safety information to health workers in a developing country setting and also proposes ways of improving this method.

\section{METHODOLOGY}

\section{Questionnaire design}

This was a descriptive correlational study using a structured questionnaire adapted from earlier study by Piening et al. (2012) and based on 3 process indicators in the Banerjee model; awareness, which measured the coverage and awareness, understanding/knowledge which assessed respondents' understanding of the information contained in the DHP letters and behavior which measures the extent of deviation from accepted behavior (Banerjee et al., 2014; Piening et al., 2012). The questionnaire was pretested using 20 respondents who were not included in the final analysis. The questionnaire was divided into 5 sections, namely; demographic characteristics, awareness/ knowledge of the of the DHP letters, quality of content/change in 
behavior, source of the letters and preferences for receiving the $\mathrm{DHP}$ letters in the future.

\section{Study design and sampling}

A descriptive correlation study was conducted of 1,098 health workers selected by convenient sampling through a face-to-face interview in all the 10 administrative regions of Ghana to access awareness, effectiveness, change in behavior and preferences for receiving DHP letters. Nine hundred and thirteen out of the 1,098 health workers contacted completed the questionnaire representing a response rate of $83.15 \%$. Respondents included doctors, pharmacists, nurses and physician assistants from public and private health facilities in Ghana. The criterion for inclusion in the study was that healthcare worker must have practiced from Jan.Dec. 2013, the period within which the DHP letters were distributed by the Food and Drugs Authority.

\section{Data collection and quality control}

The doctors, pharmacists, nurses and physician assistants were contacted through face-to-face interview from April, 2014 to June, 2014 by the Food and Drugs Authority employees in the 10 administrative regions of Ghana. The questionnaire was reviewed by 2 pharmacovigilance experts and then pretested to evaluate its appropriateness and suitability for the study. To ensure uniformity of the process, the Food and Drugs Authority employees involved in the study were trained on the methodology of administering the questionnaire and presentation of the study objectives to the respondents. The study questionnaire had 5 sections (Sections $A$ to E) which requested for information on the demographic characteristics of the responding health workers, awareness/ knowledge of the DHP letters distributed in 2013, quality of content/change in behavior; source of the letters and preferences for receiving the DHP letters in the future. No identifying information was collected from the study participants; agreement to take part in the study was considered consent.

\section{Data analysis}

Data collected during the study was entered into data editor in STATA version 13 developed by StataCorp, Texas 77845, USA. Pearson-chi square test $\left(x^{2}\right)$ was used to determine the association between region and the profession of the healthcare worker and the awareness/understanding and the preference for receiving the DHP letters. Fischer exact test $\left(\mathrm{F}^{\text {exact}}\right)$ was used to determine the association between the categorical demographic variables when the number of counts in the contingency table was less than 5. A pvalue of $<0.05$ was considered significant during the analysis.

\section{RESULTS}

Nine hundred and thirteen health workers out of 1,098 approached completed the questionnaire giving a response rate of $83.15 \%$. The professional backgrounds of the 913 health workers were $597(65.39 \%)$ pharmacists, $136(14.90 \%)$ doctors, 95 (10.40\%) nurses and 85 $(9.31 \%)$ physician assistants. All 913 completed responses were included in the analysis and the characteristic of the respondents were given in Table 1.

\section{Knowledge and behavior of the health workers}

Of the 913 health workers who completed the questionnaire only 350 (38.34\%) had knowledge of at least one of the 6 DHP letters distributed by the FDA in 2013. On the average greater \% of nurses $65(68.42 \%)$ had knowledge of at least one of the 6 DHP letters distributed compared to other health workers $\left(X^{2}=102.39\right.$, $p<0.0005)$. Figure 1 provides the \% of health workers' knowledge of the 6 DHP letters distributed. In total, more health workers who had knowledge of these letters, were aware of the letter relating to diclofenac and cardiovascular events $213(60.00 \%)$ compared to the other letters, with the least being the use of codeine for analgesia in children and adolescents $132(37.18 \%)$.

Majority of the health workers $289(82.57 \%)$ who had knowledge of the letters remember the content while the rest did not. Nurses $60(92.31 \%)$ are more likely to remember the safety issues presented in these letters compared to the other health workers $\left(\mathrm{F}^{\text {exact }}=0.040\right)$. The ability to remember the content of the letters, for other health workers varies from 37 (86.05\%), 130 (81.25\%) and $62(75.61 \%)$ for physician assistants, pharmacists and doctors, respectively. Three hundred and five $(87.14 \%)$ of the health workers who received the letters have used at least one of the medicines in their practice. Majority of the health workers $314(89.71 \%)$ admitted that the content of these letters influenced the way they prescribe, dispense or administer these medicines. All physician assistants $100 \%$ (43) who received at least one of the DHP letters reported change in their prescribing behavior. The remaining health workers reported the following percentages as changes in behavior after becoming aware of the letters; 90.24\% (74), 87.50\% (140) and $87.69 \%$ (57) for doctors, nurses and pharmacists, respectively. There was no statistically significant relationship between change in behavior and profession $\left(F^{\text {exact }}=0.144\right)$. Those who reported change in behavior stated that they were influenced to change prescribing practice and patient counseling. Those who stated that the DHP letters did not result in change in behavior stated reasons like the information is already known and the medicines involved were not used by them.

Apart from the 6 DHP letters sent in 2013, the health workers were also asked if they have ever received any letter from the FDA and out of the 911 who responded to this question , $497(54.56 \%)$ has never received any letter from the FDA and the rest did.

\section{Quality and relevance of the information}

Quality and relevance of the DHP letters were measured in terms of the used language and relevance of content. Health workers who read the letters rated the level of 
Table 1. Background characteristics of respondents.

\begin{tabular}{lcc}
\hline Characteristics (N) & Frequency & Percent (\%) \\
\hline Gender (913) & & \\
Male & 354 & 41.45 \\
Female & 500 & 58.55
\end{tabular}

\section{Age in Years (908)}

$\leq 30$

410

$31-40$

$41-50$

$\geq 51$

Profession (913)

Doctor

Pharmacist

Nurse

Physician Assistant

Number of Years practiced (853)

$\leq 2$

3-5

6-10

$\geq 10$

Type of Health Facility (908)

Government

508

270

Quasi-Government

96

34

136

597

95

85

45.15

257

127

114

13.99

12.56

Christian Health Association of Ghana

Private

192

268

172

221

14.9

65.39

10.51

9.31

\section{Region (913)}

Ashanti

$112 \quad 12.27$

Brong-Ahafo

Central

Eastern

Greater Accra

Northern

Upper East

Upper West

Volta

12.27

11.39

96

10.51

86

9.42

84

9.2

83

9.09

82

8.98

80

8.76

74 understanding of the language used as good and satisfactory, $192(54.82 \%)$ and $151(43.14 \%)$, respectively and only $2(0.57 \%)$ rated the language as poor. There was no significant difference between the health workers rating of the used language in the letters $\left(\mathrm{F}^{\text {exact }}=0.270\right)$. Those who responded to the question on the relevance of the DHP letters rated these as good and satisfactory corresponding to $235(65.73 \%)$ and 122 (34.2 7\%), respectively all those who read the letters stated that the content was relevant to their practice as health workers.

\section{Source of the DHP letters}

Majority of those who were aware of the letters 183 $(53.67 \%)$ had it directly from the Food and Drugs 


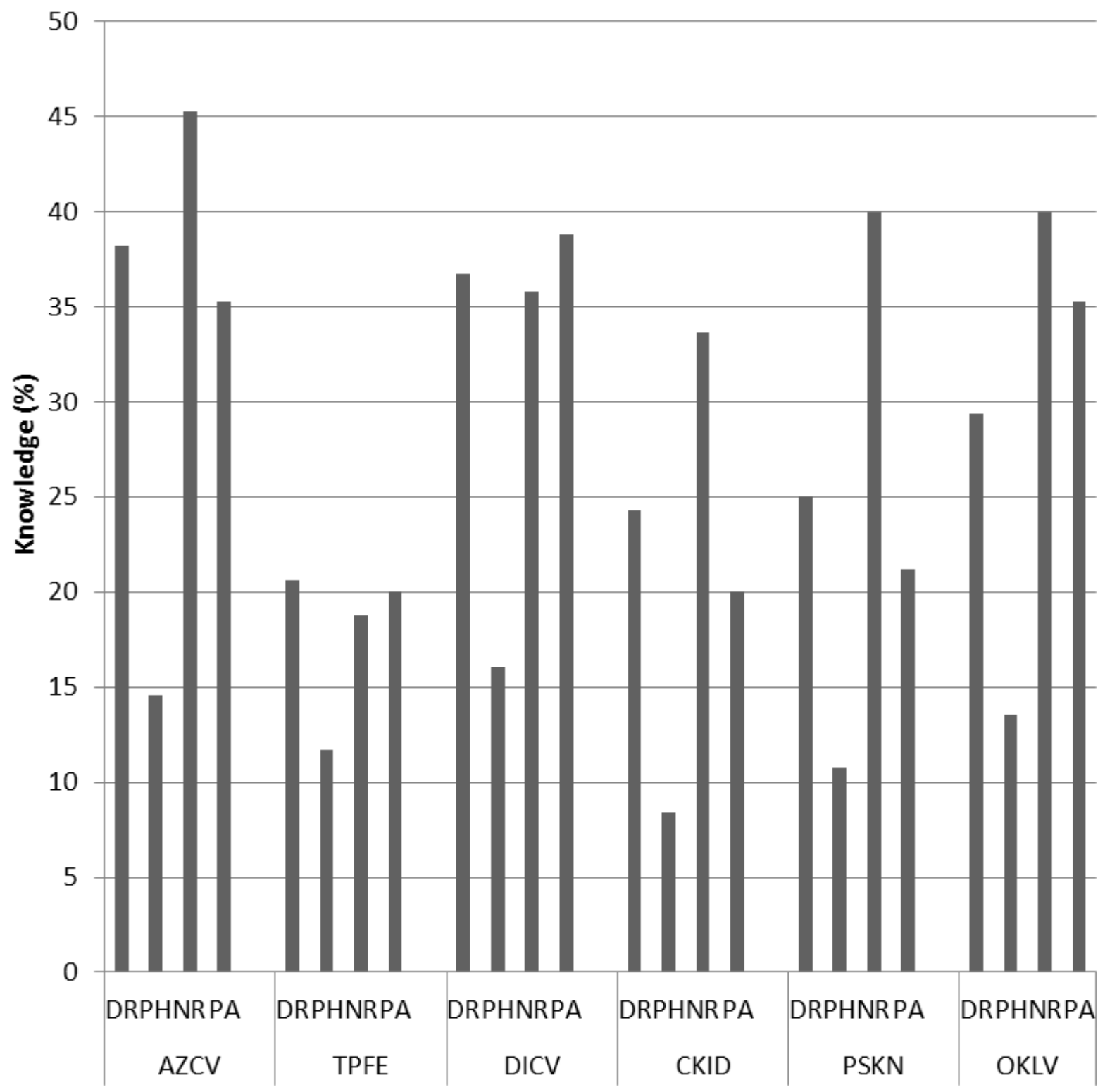

Figure 1. Health workers knowledge of six dear healthcare professional letters issued by the FDA in Jan-Dec. 2013. $\mathbf{D R}=$ Doctor; $\mathbf{P H}=$ Pharmacist; $\mathbf{N R = N u r s e ; ~} \mathbf{P A}=$ Physician Assistant; $\mathbf{A Z C V}=$ Azithromycin and cardiovascular risks; TPFE= Reporting incidents of therapeutic ineffectiveness; DICV= Diclofenac and the risk of cardiovascular events; CKID=Codeine for analgesia in children and adolescents; PSKN=Paracetamol and the risk of severe skin reactions; $\mathrm{OKLV}=$ Oral ketoconazole due to severe liver injury, adrenal gland problems and drug interactions.

Authority, followed by 136 (39.88\%) from the hospital facility where they practice. Other sources stated were from colleagues, professional associations, internet, medscape and other regulatory bodies like the Ghana Medical Council, Pharmacy Council and the Nursing and Midwifery Council. Almost all those who received the letters $318(90.86 \%)$ received them as hard copies and the rest as soft copies and 255 (72.86\%) considered the medium of delivery of these letters as effective.
One hundred and sixty one $(46.00 \%)$ of those who received the letters had them within 2 months with 134 $(38.19 \%)$ receiving these letters 2 months after they were issued. $55(15.71 \%)$ did not answer this question because they couldn't recall at what time to the issuance of these letters they were received. Almost all the regions received the letters within the same period, there is no differences among regions and how long it took to receive the letters $\left(X^{2}=27.74 ; p=0.066\right)$. 
Table 2. Preferred source of drug safety communication [n(\%)].

\begin{tabular}{lcccccc}
\hline Preferences & Doctor & Pharmacist & Nurse & $\begin{array}{c}\text { Physician } \\
\text { Assistant }\end{array}$ & Total & p-value \\
\hline Text Message & $63(46.32)$ & $282(47.24)$ & $57(60.00)$ & $36(42.35)$ & $438(47.97)$ & 0.077 \\
Professional Journal & $53(38.97)$ & $103(17.25)$ & $39(41.05)$ & $22(25.88)$ & $217(23.77)$ & 0.001 \\
Professional Meetings & $45(33.09)$ & $191(31.99)$ & $32(33.68)$ & $37(43.53)$ & $305(33.41)$ & 0.216 \\
FDA website & $37(27.21)$ & $113(18.96)$ & $35(36.84)$ & $22(25.88)$ & $207(22.70)$ & 0.001 \\
\hline
\end{tabular}

\section{Preferences for risk communication}

The most preferred means of delivering the letters to the health workers was short messaging service (SMS) to their mobile phones $438(47.97 \%)$ with the least preferred being the letters posted on the FDA website, $207(22.70 \%)$. Table 2 shows health workers and the preference for risk communication. Of the 106 health workers who answered the open questions on the other preferences for risk communication $91(85.85 \%)$ mentioned email as the preferred source, followed by social and electronic media at $10(9.43 \%)$ and $4(3.77 \%)$, respectively.

\section{DISCUSSION}

Limited number of health workers interviewed, 350 (38.34\%) had awareness of at least one of the 6 DHP letters distributed by the FDA in 2013. This is surprising because the letters were distributed to all the health facilities in which the interviews were conducted. In contrast, a similar study in the Netherlands reported higher \% of health workers' awareness, 49 to $67 \%$, of the DHP letters distributed by the Dutch regulator (Théophile et al., 2011). The low awareness of health workers about the DHP letters distributed by the FDA will result in the lack of knowledge of these issues and therefore specific actions needed to minimize risk to patients from these safety issues as revealed by Nicolette et al. (Bester et al., 2016). Encouraging is the number of health workers, 314 $(89.71 \%)$ who admitted that these letters have influenced their behavior relating to prescription, dispensing, and administration of the medicines involved. The finding in this study was better than what was obtained in similar studies (Cheung et al., 2008; Karpel et al., 2009).

Greater number of nurses, $65(68.42 \%)$ were aware of the safety issues compared to other health workers, with the least being physician assistants. More pharmacists, $70(41.92 \%)$ were aware of the safety issue regarding therapeutic ineffectiveness compared to other health workers. The fact that nurses had the greatest awareness of the letters could be explained by the fact that most of these medicines are administered by the nurses hence the interest in the safety issues regarding these medicines. The DHP letter with the best awareness amongst all health workers was; diclofenac and the risk of cardiovascular events $213 \quad(60.00 \%)$, followed azithromycin and cardiovascular risks 212 (59.72\%), with the least being the use of codeine for analgesia in children and adolescents, $132(37.18 \%)$. This could be explained by the fact that of the medicines, diclofenac and azithromycin are the most used analgesic and antibacterial agent, respectively; hence, the interest of the health workers in these safety issues (Van Boeckel et al., 2014; CDDEP, 2015; Desalegn, 2013; Teslim et al., 2014).

The use of codeine as analgesia in children and adolescent is not recommended in Ghana (Ghana Minstry of Health 2010a, b). This DHP letter is therefore considered not relevant to the health workers interviewed, hence their lack of interest, which is consistent with an earlier study (Piening et al., 2012). Four hundred and ninetyseven $(54.56 \%)$ of the health workers interviewed have never seen or received a DHP letter from the Food and Drugs Authority. This result is high compared with those obtained in studies in the USA and Netherlands where only 18 and $15 \%$, respectively which indicated that they had never seen or received a DHP letter before from these regulatory authorities (Lee et al., 2008; Piening et al., 2012).

The high number of health workers who confirmed that the letters have changed their behavior could be linked to the high ratings given to the DHP letters in terms of content, layout and quality of information contained in these letters which is consistent with the findings by the Mazor study (Mazor et al., 2005). Majority of health workers, $183(53.67 \%)$ received the DHP letters from the Food and Drugs Authority as against those received by the hospital authorities 136 (39.88\%), which showed that the Food and Drugs Authority remains the main source of safety communications. However, it is important the Food and Drugs Authority expand the distribution list to ensure a lot more health workers receive these safety communication in view of the small number who had never seen or received a DHP letter.

It took more than 2 months for $134(38.19 \%)$ to receive the DHP letters which is a major limitation in delivering the letters as these risk minimization information would not get to those who need these in real time to be able to take the decision required to improve the benefit-risk 
assessment of the medicinal products involved. To improve this situation the health workers preferred electronic means of receiving the risk communication such as short messaging service (SMS) to their mobile phones and emails.

The strengths of this study were that data was collected from health workers in all the ten regions of Ghana which constitute a representative population of health workers in Ghana, and the period between the issuance of the DHP letters and the study is quite close therefore limiting the incidence of recall bias. Limitations associated with this study were that factors related to self-reporting studies such as accuracy of recall and personal bias may affect the study because some of the health workers might not remember receiving any of the DCHP letters for which this study is based. Secondly, the sampling method used, convenient sampling, meant it may be difficult to generalize the results to the general population. Finally, to our knowledge there is no standard for measuring the overall effectiveness of DHP letters as a risk minimization tool.

\section{CONCLUSION}

The results suggest that although FDA's DHP letters are effective in changing the behavior of health workers, it is generally received late by the intended recipients. The FDA should therefore adopt electronic means such as emails and short messaging services for distributing the DHP letters to ensure optimum risk minimization. There is the need for future research on whether the change in behavior observed after reading the DHP letters by healthcare professionals was sustained to ensure patient safety.

\section{ACKNOWLEDGMENTS}

The authors wish to gratefully acknowledge Institutional Contact Persons in all health facilities where the data was collected and the FDA Regional Pharmacovigilance Officers who collected the data, listed in Appendix 1.

\section{Conflict of interests}

The authors have not declared any conflict of interest.

\section{REFERENCES}

Arnardottir AH, Haaijer-Ruskamp FM, Straus SM, Eichler HG, de Graeff PA, Mol PG (2011). Additional safety risk to exceptionally approved drugs in Europe?. Br. J. clin. Pharmacol. 72(3):490-499.

Banerjee AK, Zomerdijk IM, Wooder S, Ingate S, Mayall SJ (2014). Post-approval evaluation of effectiveness of risk minimisation: methods, challenges and interpretation. Drug Saf. 37(1):33-42.
Bester N, Di Vito-Smith M, McGarry T, Riffkin M, Kaehler S, Pilot R, Bwire R (2016). The effectiveness of an educational brochure as a risk minimization activity to communicate important rare adverse events to health-care professionals. Adv. Ther. 33(2):167-77.

Center For Disease Dynamics, Economics and Policy (CDDEP) (2015). The state of the world's antibiotics 2015. Available at: https://cddep.org/sites/default/files/swa_2015_final.pdf Accessed February 19, 2016.

Cheung A, Sacks D, Dewa CS, Pong J, Levitt A (2008). Pediatric prescribing practices and the FDA black-box warning on antidepressants. J. Dev. Behav. Pediatr. 29(3):213-215.

Desalegn AA (2013). Assessment of drug use pattern using WHO prescribing indicators at Hawassa University teaching and referral hospital, south Ethiopia: a cross-sectional study. BMC Health services Res. 13(1):1.

Dusetzina SB, Higashi AS, Dorsey ER, Conti R, Huskamp HA, Zhu S, Garfield CF, Alexander GC (2012). Impact of FDA drug risk communications on health care utilization and health behaviors: a systematic review. Med. Care 50(6):466.

European Commission (EC) (2010). Directive 2010/84/EU of the European Parliament and of the Council of 15 December 2010 amending, as regards pharmacovigilance, Directive 2001/83/EC on the Community code relating to medicinal products for human use. Available at: http://ec.europa.eu/health/files/eudralex/vol1/dir_2010_84/dir_2010_84_en.pdf Accessed February 16, 2016.

European Medicines Agency (EMA) (2014). Guidelines on good pharmacovigilance practice. GVP Module XVI. http://www.ema.europa.eu/docs/en_GB/document_library/Scientific_g uideline/2014/02/WC500162051.pdf Accessed February 16, 2016.

Food and Drugs Authority Ghana (2013a). Azithromycin and cardiovascular risks. Available at: http://www.fdaghana.gov.gh/images/stories/pdfs/Dear\%20Helthcare \%20Prof/ Accessed February 16, 2016.

Food and Drugs Authority Ghana (2013b). Diclofenac and risk of cardiovascular events (heart attack and stroke). Available at: http://www.fdaghana.gov.gh/images/stories/pdfs/Dear\%20Helthcare \%20Prof/ Accessed February 16, 2016.

Food and Drugs Authority Ghana (2013c). Oral ketoconazole and the risk of severe liver injury, adrenal gland problems and harmful drug interactions. Available http://www.fdaghana.gov.gh/images/stories/pdfs/Dear\%20Helthcare \%20Prof/ Accessed February 16, 2016.

Food and Drugs Authority Ghana (2013d). Paracetamol and the risk of rare but serious skin reactions. Available at: http://www.fdaghana.gov.gh/images/stories/pdfs/Dear\%20Helthcare \%20Prof/ Accessed February 15, 2016.

Food and Drugs Authority Ghana (2013e). Reporting incidents of therapeutic ineffectiveness as adverse events. Available at : http://www.fdaghana.gov.gh/images/stories/pdfs/Dear\%20Helthcare \%20Prof/ Accessed February 16, 2016.

Food and Drugs Authority Ghana (2013f). Restrictions on the use of codeine as an analgesic in children and adolescents. Available at : http://www.fdaghana.gov.gh/images/stories/pdfs/Dear\%20Helthcare \%20Prof/ Accessed February 16, 2016.

Ghana Ministry of Health (2010a). Ghana essential medicines List. Available

at: http://apps.who.int/medicinedocs/documents/s18014en/s18014en.pd f. Accessed February 22, 2016.

Ghana, Ministry of Health (2010b). Standard Treatment Guidelines. Available at: http://apps.who.int/medicinedocs/documents/s18015en/s18015en.pdf Accessed February 26, 2016

Giezen TJ, Mantel-Teeuwisse AK, Straus SM, Schellekens H, Leufkens $H G$, Egberts AC (2008). Safety-related regulatory actions for biologicals approved in the United States and the European Union. Jama 300(16):1887-1896.

Graham DJ, Drinkard CR, Shatin D, Tsong Y, Burgess MJ (2001). Liver enzyme monitoring in patients treated with troglitazone. Jama 286(7):831-833.

Karpel JP, Peters JI, Szema AM, Smith B, Anderson PJ (2009). 
Differences in physicians' self-reported knowledge of, attitudes toward, and responses to the black box warning on long-acting betaagonists. Ann. Allergy Asthma Immunol. 103(4):304-310.

Lee LY, Kortepeter CM, Willy ME, Nourjah P (2008). Drug-risk communication to pharmacists: assessing the impact of riskminimization strategies on the practice of pharmacy. J. Am. Pharm. Assoc. 48(4):494-500.

Mazor KM, Andrade SE, Auger J, Fish L, Gurwitz JH (2005). Communicating safety information to physicians: an examination of dear doctor letters. Pharmacoepidemiol. Drug Saf. 14(12):869-875.

Piening S, Haaijer-Ruskamp FM, de Vries JT, van der Elst ME, de Graeff PA, Straus SM, Mol PG (2012). Impact of safety-related regulatory action on clinical practice: a systematic review. Drug Saf. 35(5):373-385.

Qureshi ZP, Seoane-Vazquez E, Rodriguez-Monguio R, Stevenson KB, Szeinbach SL (2011). Market withdrawal of new molecular entities approved in the United States from 1980 to 2009. Pharmacoepidemiol. Drug Saf. 20(7):772-777.

Raine J, Wise L, Blackburn S, Eichler HG, Breckenridge A (2011). European perspective on risk management and drug safety. Clin. Pharmacol. Ther. 89(5):650-654.

Reber KC, Piening S, Wieringa JE, Straus SM, Raine JM, de Graeff PA, Haaijer-Ruskamp FM, Mol PG (2012). When direct health-care professional communications have an impact on inappropriate and unsafe use of medicines. Clin. Pharmacol. Ther. 93(4):360-365

Teslim OA, M'Kumbuzi V, Olaogun MO, Onigbinde AT, Oluwafisayo AJ, Nondwe BM, Manie S, Tarimo N, Mukoka G (2014). Side effects of non-steroidal anti-inflammatory drugs: the experience of patients with musculoskeletal disorders. Am. J. Health Res. 2(4):106.
Théophile $H$, Miremont-Salamé G, Robinson $P$, Moore $\quad N$, Bégaud $B$, Haramburu F (2011). Relevance of a 'dear doctor letter' to alert healthcare providers to new recommendations for vitamin D administration. Eur. J. Clin. Pharmacol. 67(7):681-686.

US Food and Drugs Administration (USFDA) (2010). Dear health care provider letters: improving communication of important safety information. Available http://www.fda.gov/downloads/drugs/guidancecomplianceregulatoryin formation/guidances/ucm233769.pdf. Accessed February 17, 2016.

US Food and Drugs Administration (USFDA) (2009). Guidance for industry format and content of proposed risk evaluation and mitigation strategies (REMS), REMS Assessments, and Proposed REMS Modifications. Available at: http://www.fda.gov/downloads/Drugs/.../Guidances/UCM184128.pdf Accessed February 23, 2016.

Van Boeckel TP, Gandra S, Ashok A, Caudron Q, Grenfell BT, Levin SA, Laxminarayan (2014). Global Antibiotic Consumption 2000 to 2010: An analysis of national pharmaceutical sales data. Lancet Infect. Dis. 14:70780-70787. 
Appendix 1. FDA Regional Pharmacovigilance Officers.

\begin{tabular}{ll}
\hline Name & Region \\
\hline Abu Sumaila & Western \\
Abena Esia-Donkoh & Western \\
Martin Kusi & Central \\
Nana Ansah Adjei & Eastern \\
Vigil Prah-Eshun & Ashanti \\
Abigail Attah & Ashanti \\
Geoffrey Arthur & Volta \\
Matthew Nkum & Brong Ahafo \\
Akosua B. Adjei & Brong Ahafo \\
Sylvester Kyei & Northern \\
Gordon Akurugu & Upper West \\
Zakaria Braimah & Upper East \\
\hline
\end{tabular}

